\title{
Study of Masking Effect of Cable and Practical Analysis of FM, VHF and UHF Broadcasting Antenna
}

\author{
Pardeep Pathania and Mritunjay Kumar Rai ${ }^{*}$ \\ School of Electronics and Electrical Engineering, Lovely Professional University, Jalandhar-Delhi, G. T. Road, \\ National Highway 1, Phagwara - 144411,Punjab, India; patddgsp@gmail.com, raimritunjay@gmail.com
}

\begin{abstract}
Antenna is a very important part of a communication system. For proper working of a terrestrial communication system antenna parameters such as return loss and standing wave ratio should be checked regularly. In this research paper practical measurement based analysis of FM, VHF and UHF antenna parameters has been carried out. In order to complete this work four numbers All India Radio and Doordarshan terrestrial transmission sites has been selected in Punjab and Himachal Pradesh. Measurement has been taken while repair of the antennas has been carried out at the respective site with Anritsu site master. It is observed that even a very small amount of water drops inside the junction box of an antenna and loose connector can predict different antenna behavior and increases reflection. Cable loss also holds importance while taking measurements. If the masking effect of cable has not been considered then it may have that our measured parameters at the transmitter could predict different antenna behavior than actually at the antenna. So masking effect of cable should be taken care of if cable loss is high.
\end{abstract}

Keywords: Antenna, Reflection Coefficient, Return Loss, Standing Wave Ratio

\section{Introduction}

An antenna is a very important subpart of a communication system. An antenna transform electrical signal from transmitter into electromagnetic waves into free space. Antenna also exhibit reciprocity principle i.e. it can transmit as well as receive without changing its characteristics". Every antenna is designed for particular frequency. Antenna can be classified on the basis of frequency, aperture, polarization and radiation pattern? For FM, VHF and UHF application Omni directional antenna are used for transmitting signal into free space. Omni directional antennas are those which transmit signal equally in all direction. There are two important characteristics of antenna which determine mismatch between source and load i.e. antenna. Antenna must be terminated with $50 \mathrm{ohm}$ impedance for broadcasting applications in order to transfer maximum power into free space. Return loss and Standing wave ratio are the two characteristics which determine proper functioning of antennal. These two characteristics can either be calculated from the given formulas or can be measured with the available instrument such as Anritsu site master etc. One cannot define working of an antenna with only multimeter but has to measure return loss and standing wave ratio for actually defining antenna working properly with some suitable instrument.

Return loss of an antenna given as:

$R L(d B)=10 \log _{10}\left[P_{\text {fwd }} / P_{\text {ref }}\right]$

Return loss can be defined with reflection coefficient as below

$$
\begin{aligned}
\mathrm{RL} & =10 \log _{10}\left|1 / \rho^{2}\right| \\
& =-20 \log _{10}|\rho|
\end{aligned}
$$

Where $\rho=\left(\mathrm{P}_{\text {ref } / \text { fwd }} \mathrm{P}_{\text {f }}\right)^{1 / 2}$

$\rho$ is reflection coefficient

Voltage standing wave ratio is defined as ratio of maximum to minimum voltage of antenna.

$\operatorname{VSWR}=\frac{1+\rho}{1-\rho}$ 
When measuring return loss and standing wave ratio one should also take care of masking effect of cable. RF cable carry signal from transmitter to antenna and also has some loss which is normally given in $\mathrm{dB}$ per feet. It may give us wrong idea in respect to return loss and standing wave ratio of antenna if we did not considered masking effect of cable? When we measure these two parameters directly at antenna, then it is possible that results are totally different. So if cable loss is more then one should take care of this masking effect of cable while measuring antenna parameters with the help of Anritsu site master.

\section{Methodology}

For this research paper measurement of return loss and standing wave ratio are taken with Anritsu site master. Four different All India Radio and Doordarshan stations have been selected. Return loss and standing wave ratio graph has been taken while repairing antenna at particular transmission site. A comparative analysis has been carried out and discussed for different graphs. In the measurements of these graphs cable loss has not been considered. For one station i.e. Doordarshan relay centre Gurdaspur the cable loss has been considered and practical impact of this cable loss on antenna parameters has been calculated and discussed. The technical details of selected sites are given below.

As above given in table 1, Chawari and Bharmour stations are situated in Himachal Pradesh in District Chamba and are unmanned stations. These two stations are being operated on solar power.

\section{Results and Discussion}

Below given are the return loss and standing wave ratio graphs of DD very low power transmitter Chawari. It has been seen from the Figure 1 and 2 that antenna characteristics are beyond limits and which shows antenna behavior is not proper. Return loss of $-17.14 \mathrm{~dB}$ and reflection coefficient of 0.139 shows transmitted power in percentage as 98.07 .

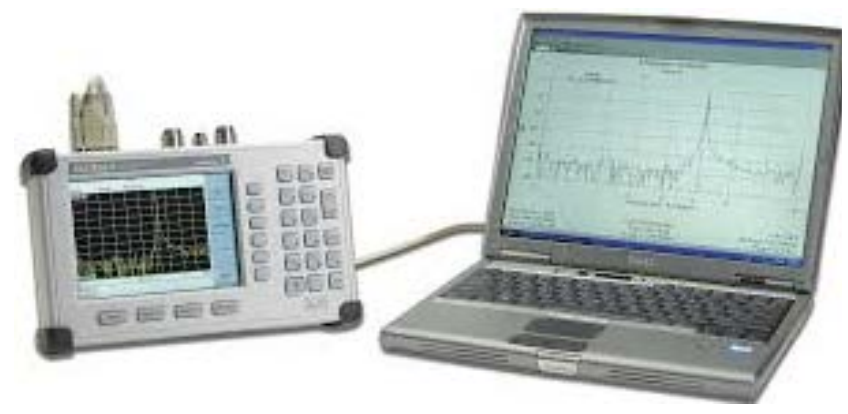

Figure 1. Anritsu Site Master.

Table 1. Technical detail of selected RF sites

\begin{tabular}{lcccc}
\hline Name of station & $\begin{array}{c}\text { Power (p-p } \\
\text { in Watt) }\end{array}$ & $\begin{array}{c}\text { Band } \\
\text { Frequency in } \\
\text { MHz \& Ch. }\end{array}$ & Antenna height \\
\hline DD Relay centre Gurdaspur (PB.) & 500 & UHF & $527.25 \& 28$ & 45 meter \\
DD very low power transmitter Chawari (HP.) & 10 & VHF & $217.25 \& 11$ & 30 meter \\
FM Radio transmitter Bharmour (HP.) & 100 & FM & 101.3 & 30 meter \\
FM Radio transmitter Gurdaspur (PB.) & 100 & FM & 100.1 & 45 meter \\
\hline
\end{tabular}

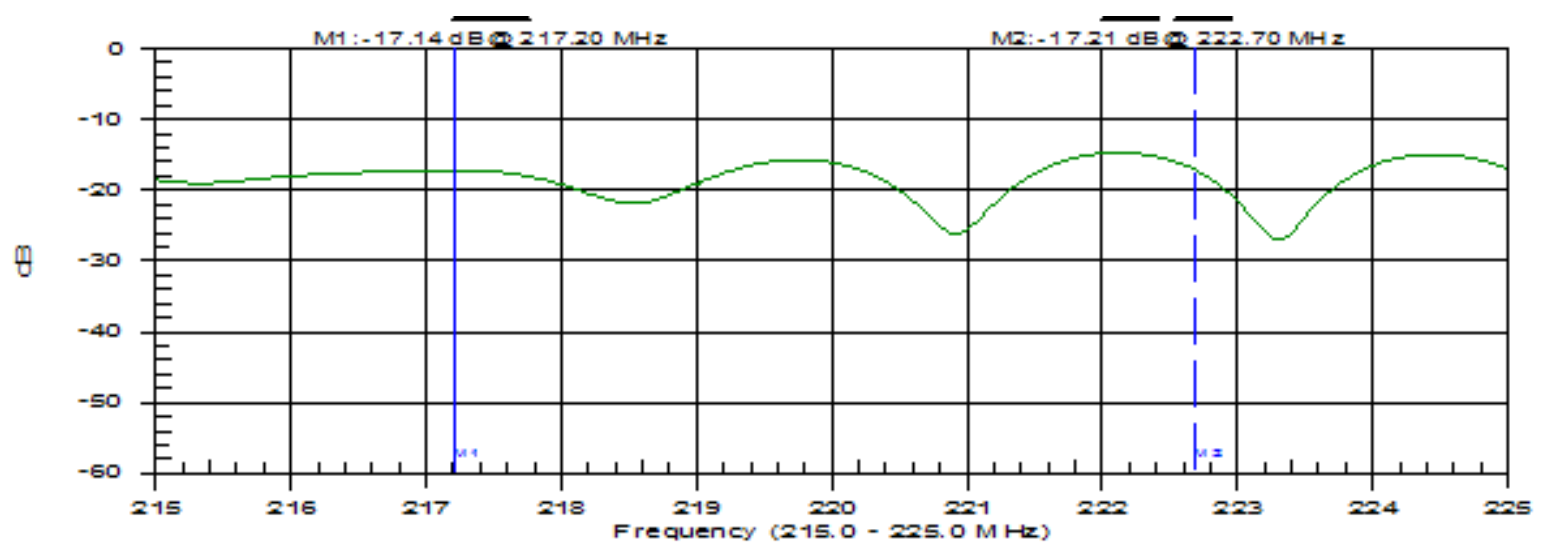

Figure 2. Return loss of graph Chawari VHF antenna. 
On checking the antenna with simple multimeter, the results are as good as normal antenna. It is not possible to define antenna working with simple multimeter. After lowering down the antenna it has been seen that water vapors get trapped inside the antenna junction box and also RF connector inside the junction box found loose. Due to these very small amount of water vapors and loose RF connector, antenna was showing abnormal characteristics. Job of cleaning the junction box, removing all the trapped water drops inside and properly sealing the junction box has been carried out and finally again the two characteristics has been measured with the Anritsu site master as shown in Figure 3 and 4.

The results as given in above tables shows return loss of $-24.66 \mathrm{~dB}$ and reflection coefficient is 0.0585 . Improvement in return loss increases the transmitted percentage power as 99.66 and decreases the reflection.

Figure 5 and 6 shows the return loss and standing wave ratio graph of FM radio Bharmour. Return loss of -17.47 shows reflection coefficient of 0.133 and transmitted percentage power as 98.21 .

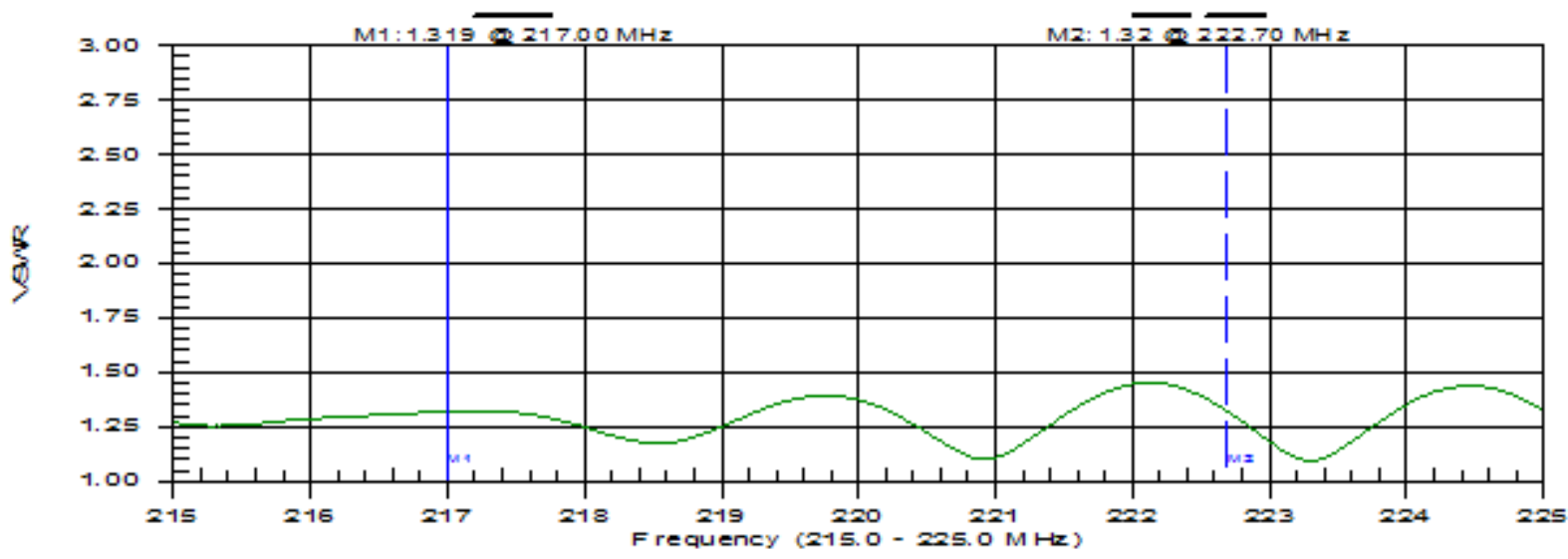

Figure 3. Standing wave ratio graph of Chawari VHF antenna.

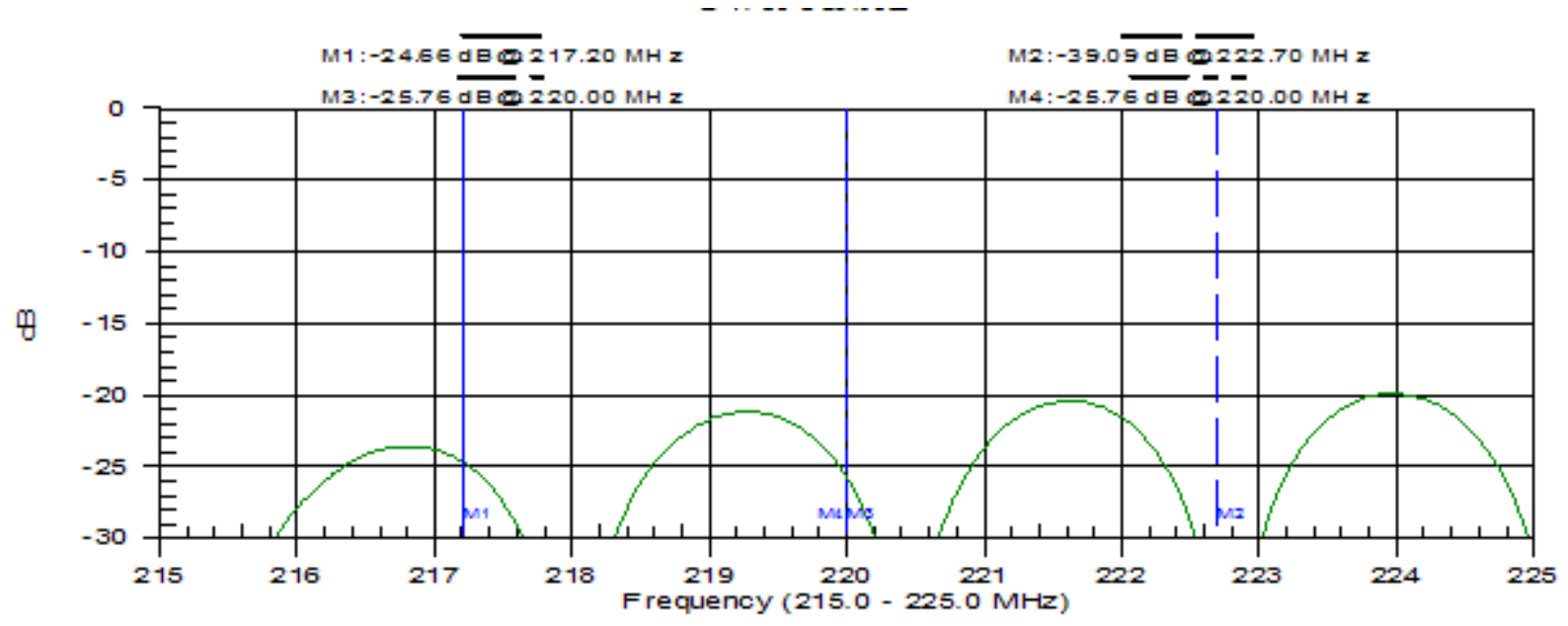

Figure 4. Return loss graph of Chawari VHF antenna after repair. 


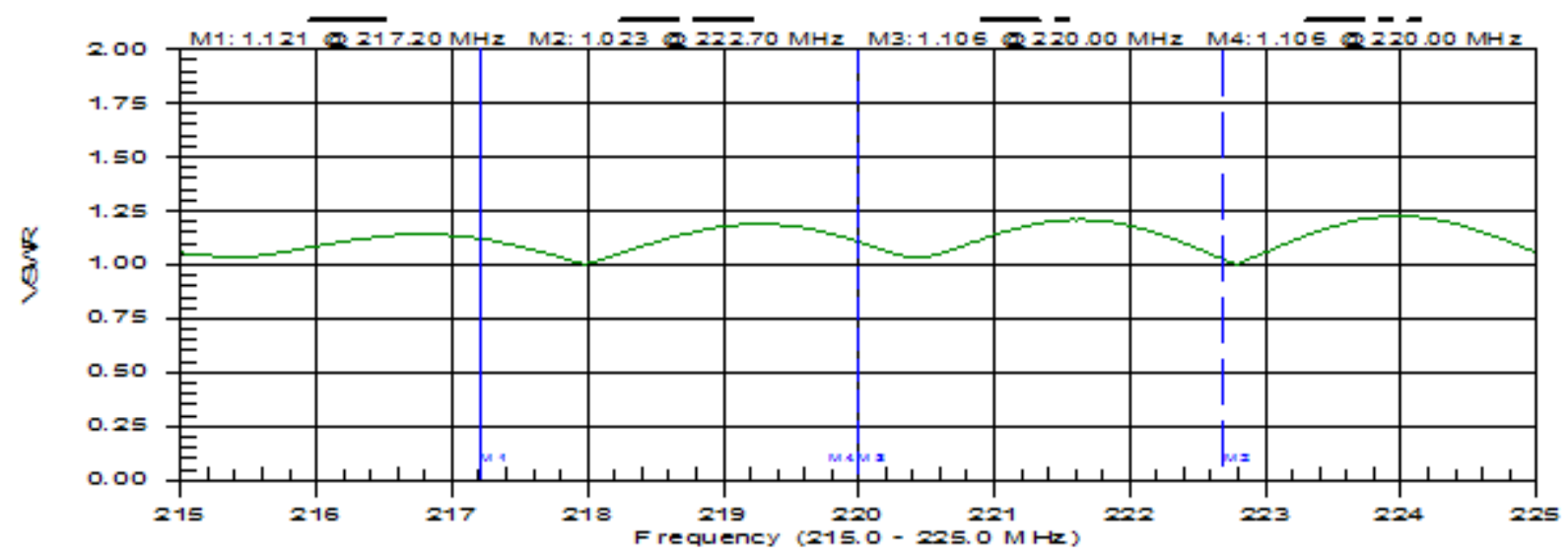

Figure 5. Standing wave ratio graph of Chawari VHF antenna after repair.

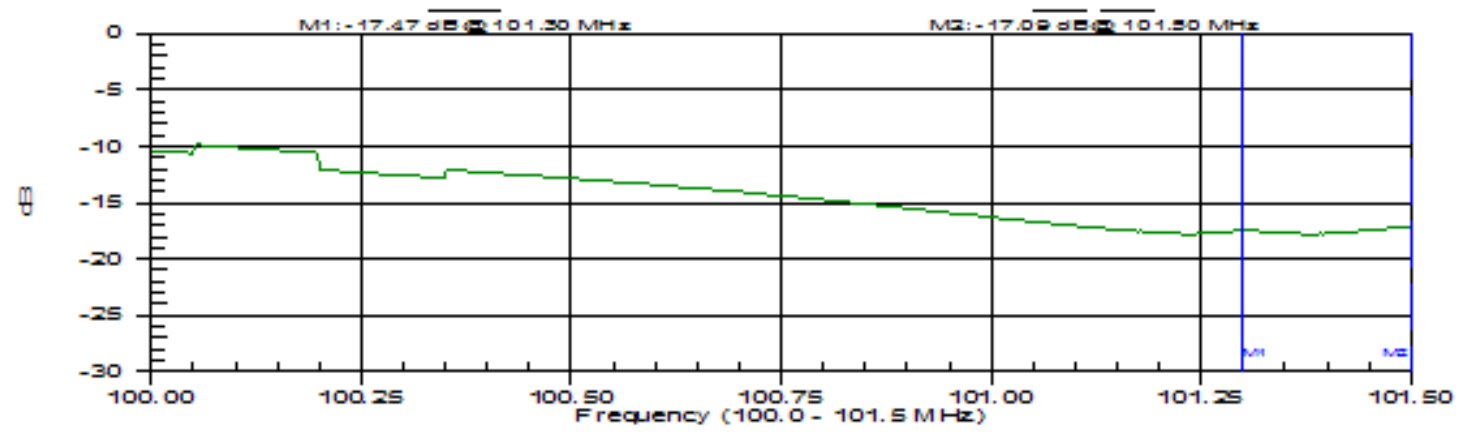

Figure 6. Return loss graph of Bharmour FM antenna.

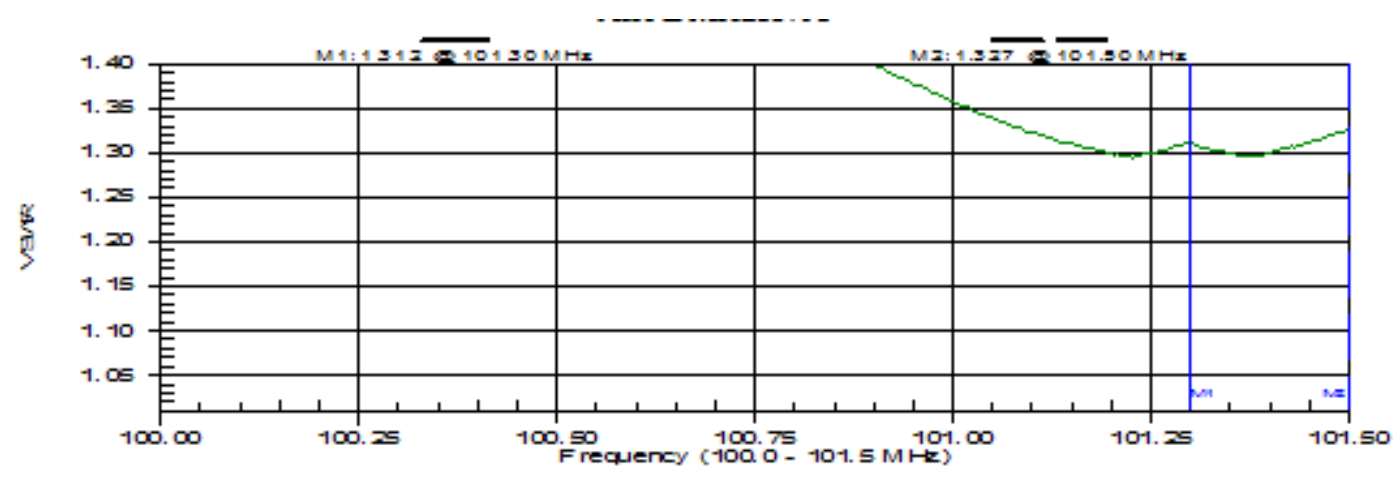

Figure 7. Standing wave ratio graph of Bharmour FM antenna.

It has been compared with one FM radio transmitter at Gurdaspur. It has been seen from the comparative characteristics of both the stations that antenna of FM Gurdaspur is having better performance characteristics than the Bharmour.

It may be due to some loose connector that is connecting at top end of antenna in Bharmour. So it has been concluded that even a small amount of loose connection between cable and antenna could predict antenna behavior abnormal. A return loss of -30.49 $\mathrm{dB}$ shows reflection coefficient as 0.0299 with increase in percentage transmitted power from 98.21 to 99.91 . Increase in percentage transmitted power further reduces reflection and which increases the efficiency of the transmitter. 


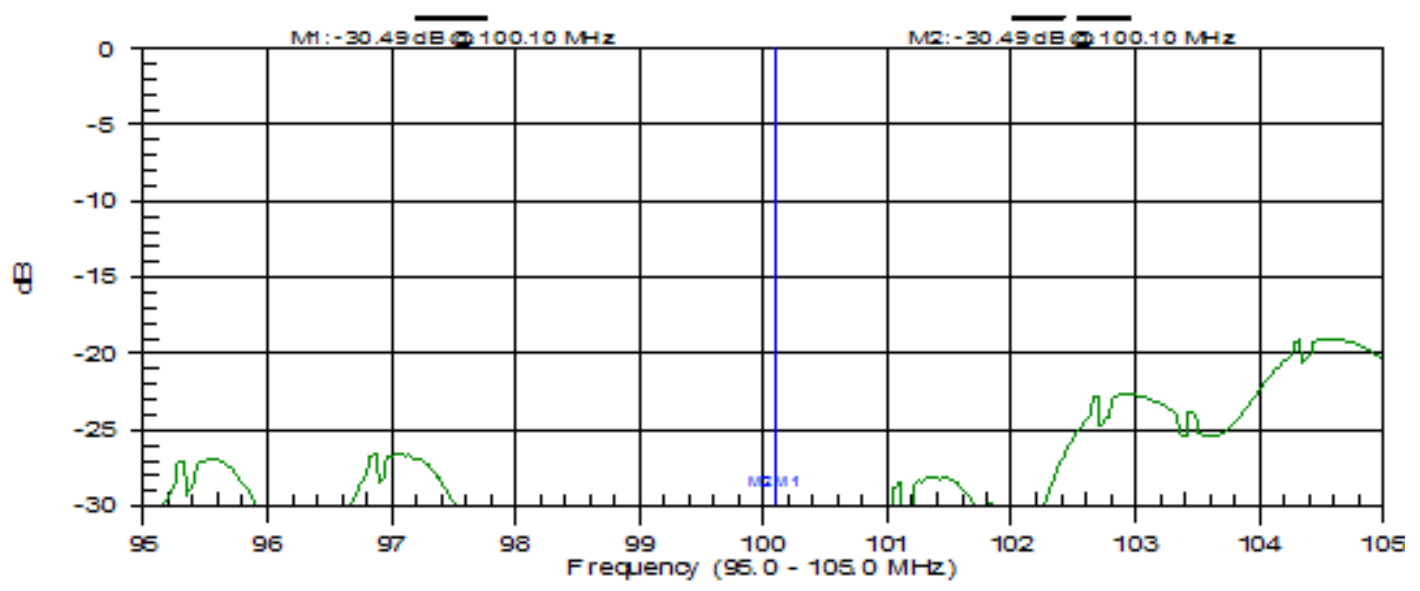

Figure 8. Return loss graph of Gurdaspur FM antenna.

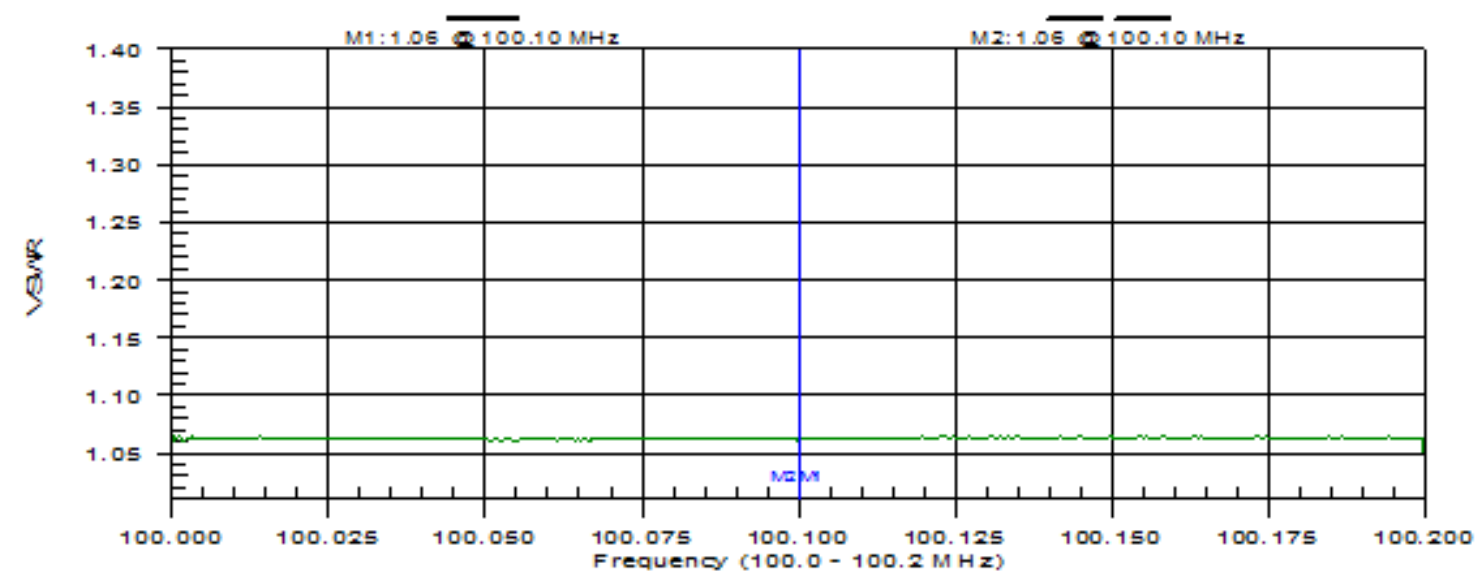

Figure 9. Standing wave ratio graph of Gurdaspur FM antenna.

Figure 9 shows the return loss graphs of DD relay centre Gurdaspur, which is being operated in UHF band at frequency of $527.25 \mathrm{MHz}$. Return loss of $-4.35 \mathrm{~dB}$ shows a reflection coefficient of 0.606 , which drastically reduces the percentage transmitted power as 63.27 and increase the reflection.

A large amount of water found trapped inside the antenna due to leakage in the Teflon sheet attached with the antenna. After properly removing the water particles and sealing the antenna with silicon sealant, the antenna hauled up on the mast. Results received after measurements are given below in Figure 10 and 11. A return loss parameter of -23.78 shows reflection coefficient as 0.0647 and in percentage transmitted power is 99.58 . 


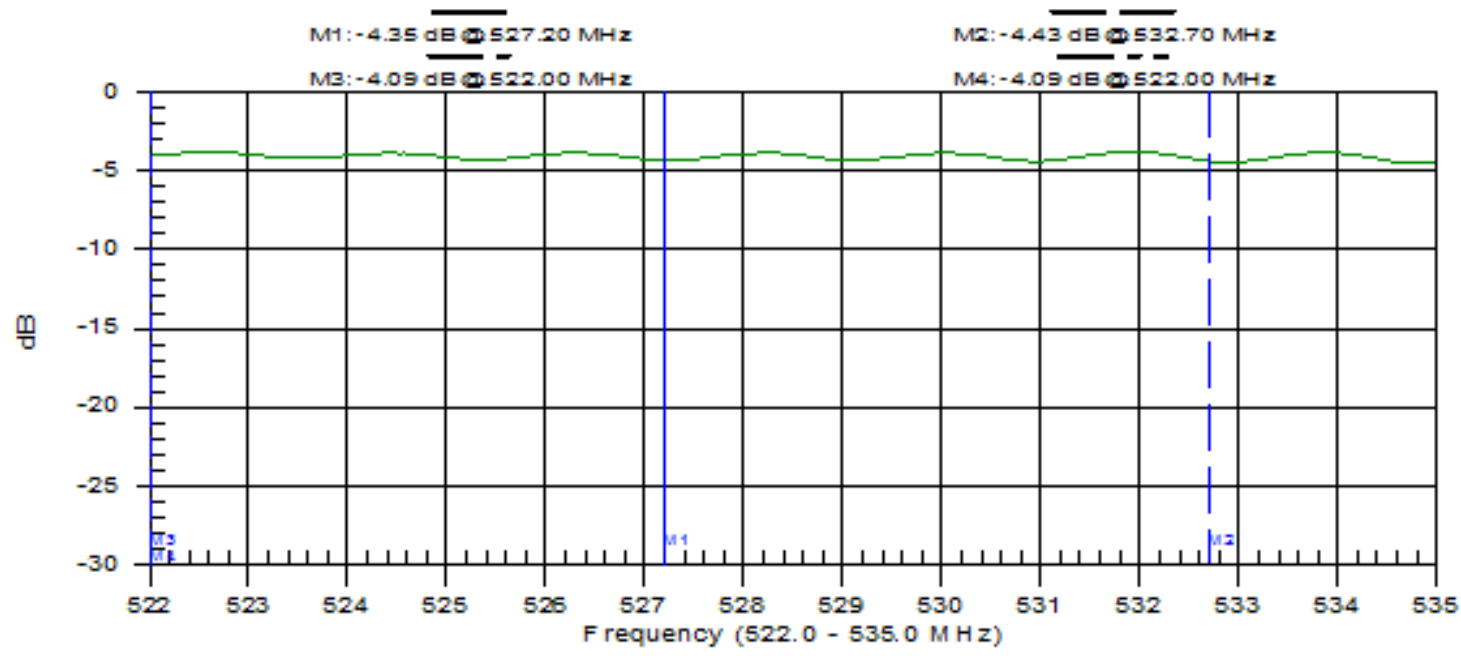

Figure 10. Return loss graph of Gurdaspur UHF TV antenna.

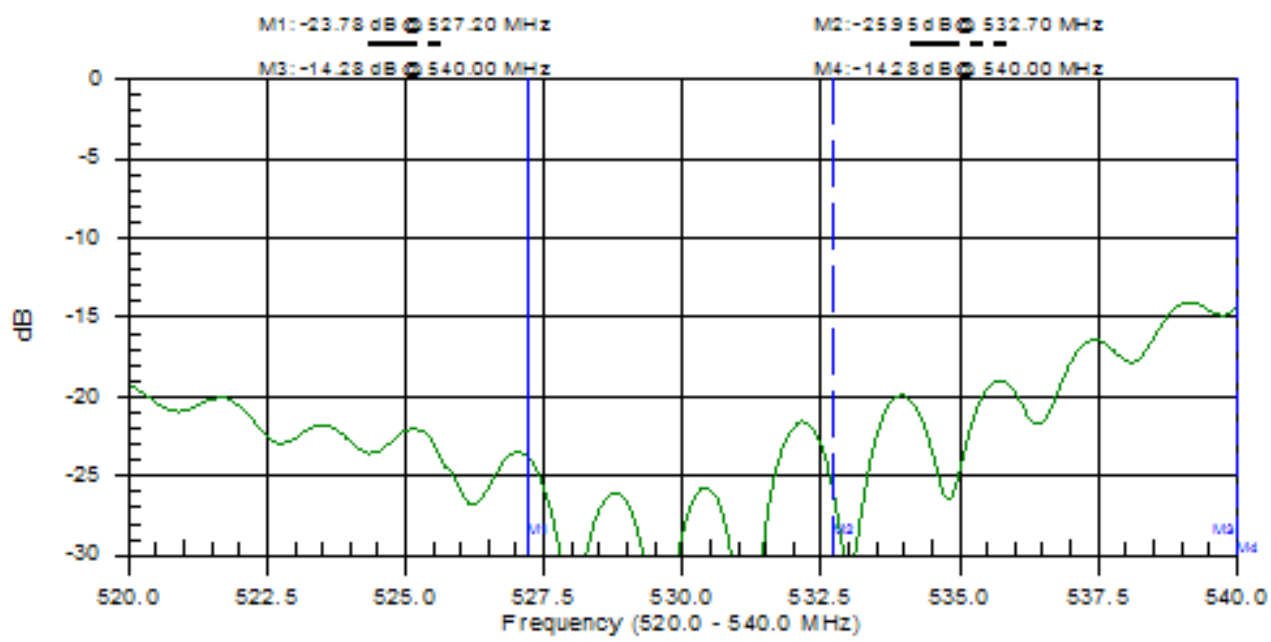

Figure 11. Return loss graph of Gurdaspur UHF TV antenna after repair.

Now the masking effect of cable at Gurdaspur has been taken in calculating the exact impact of cable loss on the antenna parameters.

Forward power of transmitter $=500 \mathrm{~W}$

Loss (cable, jumper and connector etc.) $=2 \mathrm{~dB}$

Forward power in $\mathrm{dB}=27$

Forward power in $\mathrm{dBm}=57$

Forward power at antenna $=$ Forward power at transmitter

- Cable loss $=57-2=55 \mathrm{dBm}$

Forward power at antenna in watts $=316$

Return loss and SWR measured with Anritsu site master at transmitter are as given below.

Return loss at transmitter $=-23.78 \mathrm{~dB}$

Cable loss $=2 \mathrm{~dB}$

Reflected power at transmitter calculated by manipulating the return loss formula as below.
Return loss $=10 \log _{10} \frac{\mathbf{P}(\text { forward })}{P(\text { reflected })}$

Reflected Power $=1.32 \mathrm{~W}$

Reflected power in $\mathrm{dBm}=31.20$

Reflected power at antenna $=$ Reflected power at transmitter + Cable loss $=31.20+2=33.20 \mathrm{dBm}=2.089$ Watt

SWR and return loss at antenna:

Rho at antenna $\rho=\left(\mathrm{P}_{\text {ref }} / \mathrm{P}_{\text {fwd }}\right)^{1 / 2}=(2.089 / 316)^{1 / 2}=0.081$

Return loss as per (3) is equal to $-21.83 \mathrm{~dB}$

SWR as per (4) is equal to 1.176

A comparative table of return loss and SWR, with and without masking effect of cable is given below. 


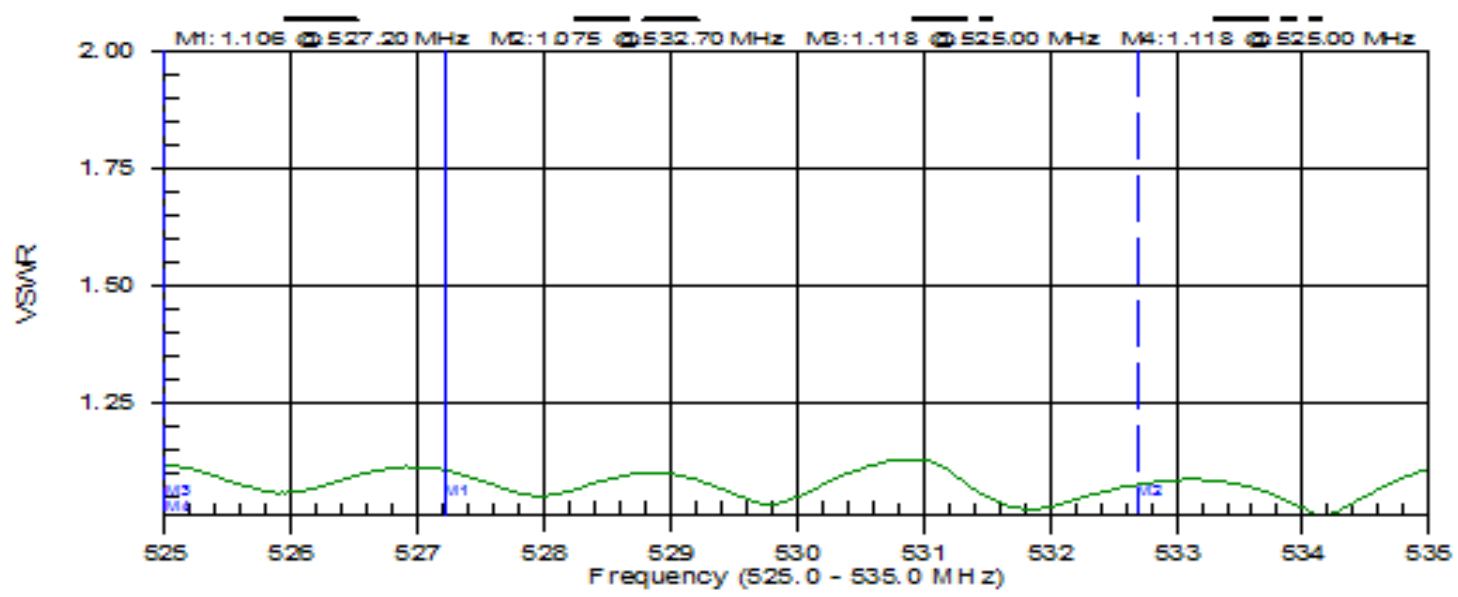

Figure 12. Standing wave ratio graph of Gurdaspur UHF TV antenna after repair.

Table 2. Comparative effect of cable loss on antenna parameters

\begin{tabular}{lcc}
\hline Antenna Parameters & $\begin{array}{c}\text { Without masking } \\
\text { effect of cable }\end{array}$ & $\begin{array}{c}\text { With masking } \\
\text { effect of cable }\end{array}$ \\
\hline Return Loss & $-23.78 \mathrm{~dB}$ & $-21.83 \mathrm{~dB}$ \\
SWR & 1.14 & 1.176 \\
\hline
\end{tabular}

There is a difference of $2 \mathrm{~dB}$ approximately for return loss in the comparative table. It has been concluded from the above table that cable masking effect plays an important role in analyzing the antenna characteristics. If the cable loss is more then it may have that antenna characteristics could be predicted wrong if masking effect of cable has not been taken into calculations.

\section{Conclusion}

From the above discussed practical analysis and discussion on the FM, VHF and UHF antennas it has been concluded that even a very small amount of water particles can predict different antenna behavior than normal. So before hauling up antenna on the mast it should be properly checked for any type of water seepage and sealed properly. Connector connecting the antenna inside the junction box should be tightened sufficient to avoid any type of loose connection. Masking effect of cable also hold importance while measuring Return loss and SWR. A comparable cable loss can cause sufficient change in Return loss and SWR. If the cable loss is high and measurement has been carried out without considering the loss then it may have that we should not be able to define actual behavior of antenna on the basis of RL and SWR.

\section{References}

1. Elrashidi A and Elleithy K, et. al. Input Impedance,VSWR and Return Loss of a Conformal Microstrip Printed Antenna for $\mathrm{TM}_{01}$ Mode using two different Substrates. International Journal of Network and Communication. 2012; 2(2):13-19.

2. Raab FH and Caverly R, et. al. HF, VHF and UHF System and Technology. IEEE Transaction on Microwave Theory and Techniques. 2002; 50(2):888-99.

3. Understanding Cable and Antenna analysis. Available from: www.anritsu.com.

4. Dhande P. Antenna and Its Applications. DRDO Science Spectrum. 2009; p. 66-78.

5. Bird TS. Definition and Misuse of Return Loss. IEEE Antenna \& Wave Propagation Magazine. 2009.

6. Effect of Cable Loss in VSWR and Return Loss Measurement, Bird System/Application Engineering.

7. Tiwari VK and Kimothi A, et. al. Theoretical and Experimental Investigation of Circular sector and Microscopic antenna. Indian Journal of Radio and Space Physics. 2006; 35:206-11.

8. Meyer L. Calculating Antenna system Return Loss as viewed through the RF path. Available from: www.andrew. com.

9. Raju GSN. Pearson Education: Antenna and Wave Propagation. 2005.

10. Prasad KD. New Delhi: Satya Prakahan: Antenna and Wave Propagation. 